\title{
Exclusive breastfeeding and associated factors among mothers in Debre Markos, Northwest Ethiopia: a cross-sectional study
}

Getnet Mekuria ${ }^{1 * \dagger}$ and Melkie Edris ${ }^{2+}$

\begin{abstract}
Background: Exclusive breastfeeding is the most widely known and effective intervention for preventing early-childhood deaths. Optimum breastfeeding practices can prevent 1.4 million deaths worldwide among children under five every year. The aim of this study was to assess the prevalence of exclusive breastfeeding and associated factors among mothers who have an infant less than six months old in Debre Markos, Northwest Ethiopia.

Methods: A community based cross-sectional study was conducted from April 1 to 30, 2013. A simple random sampling technique was used from a list of all mothers who had an infant less than six months old obtained from the health extension workers (HEWs) registration book in all kebeles (neighbourhoods) of the city. A total of 423 mothers with infants less than six months old were included in this study. Data were collected using questionnaires administered at interview. Both bivariate and multivariate logistic regression analyses were carried out to identify factors associated with exclusive breastfeeding.

Results: The prevalence of exclusive breastfeeding during the seven days before the survey was $60.8 \%$ (95\% Cl: 55.8\%, $65.8 \%)$. Those mothers who were unemployed $[\mathrm{AOR}=1.98(1.21,3.22)]$, received breastfeeding counseling during antenatal care (ANC) $[A O R=2.44(1.53,3.91)]$, received infant feeding counseling during postnatal care (PNC) $[A O R=5.03$ $(3.04,8.31)]$, didn't give prelacteal feeding $[A O R=3.44(1.88,6.33)]$ and had adequate knowledge about breastfeeding $[A O R=2.57(1.57,4.19)]$ were more likely to practice EBF than their counterparts.

Conclusions: Although the prevalence of exclusive breastfeeding was lower in the study area than international recommendations, rates were higher than found in other studies. Recommendations for improving exclusive breastfeeding include better support for working mothers through extending maternal leave and establishing work-site day care centers for infants, expanding the urban health extension program so that more pregnant women and mothers can be taught about appropriate infant and young child feeding practices and how to express their milk, thereby increasing their breastfeeding knowledge.
\end{abstract}

\section{Background}

Breast milk is a natural, renewable food that serves as a complete source of infant nutrition for the first six months of life. It has the appropriate balance of nutrients provided in a bio-available and easily digestible form, protecting both mothers and children against illnesses and diseases with unparalleled immunological and anti-inflammatory properties [1].

\footnotetext{
* Correspondence: getnetmekuria70@yahoo.com

${ }^{\dagger}$ Equal contributors

${ }^{1}$ College of Medicine and Health Sciences, Department of Public Health, Debre Markos University, Debre Markos, Ethiopia

Full list of author information is available at the end of the article
}

Exclusive breastfeeding is defined as feeding an infant with only breast milk and no additional food, water, or other liquids (with the exception of medicines and vitamins, if needed) during the first six months of life. Infants who are exclusively breastfed have less chance of becoming ill or dying from diarrhoea and other infections. In addition, they are less likely to acquire pneumonia, meningitis, and ear infections than non-breastfeed infants [2]. Exclusive breastfeeding is the most widely known and effective intervention for preventing early-childhood deaths. Optimum breastfeeding practices can prevent 1.4 million deaths worldwide among children under five every year [3]. Suboptimal breastfeeding contributes to $45 \%$ of 
neonatal infectious deaths, $30 \%$ of diarrheal deaths and $18 \%$ of acute respiratory deaths among children under five in developing countries [4]. It is also responsible for $10 \%$ of the disease burden in children younger than 5 years old [5].

Globally, fewer than 35\% of infants are exclusively breastfed during the first four months of life [6]. In developing countries, just 37\% of infants less than 6 months old are exclusively breastfed. In Africa, less than one third of infants under 6 months old are exclusively breastfed [7].

In Ethiopia approximately half (52\%) of children less than six months old are exclusively breastfed. The practice of EBF at age $0-1$ month is $70 \%, 55 \%$ at $2-3$ months and 32\% among 4-5 month old infants [8]. The Health Sector Development Program (HSDP) IV has set a target to increase exclusive breastfeeding from $49 \%$ to $70 \%$ in Ethiopia by the end of 2015 [9]. Therefore, this study is important to determine the prevalence of exclusive breastfeeding and to identify the factors that may act as barriers to mothers' exclusively breastfeeding.

\section{Methods}

\section{Study setting and participants}

A community based cross-sectional study was conducted from April 1 to 30, 2013 in Debre Markos, located $265 \mathrm{~km}$ Northwest of Addis Ababa, Ethiopia. The town has seven kebeles, one Government hospital and three health centers. It has an estimated total population of 86,786, including 1,129 infants less than 6 months old.

The sample size was calculated by using a single population proportion formula with the following considerations; prevalence of exclusive breastfeeding practice (51.8\%) from previous research conducted in Harar, Eastern Ethiopia [10], 95\% confidence level, 5\% margin of error and a $10 \%$ non-response rate. A total of 423 mothers were selected using a simple random sampling technique from a list of all mothers who had an infant less than six months old, obtained from the health extension workers registration book.

\section{Measurements}

A questionnaire administered at interview was used to collect data from mothers. First, the English version of the questionnaire was prepared, translated to Amharic and then back to English by language translators in order to check for consistency. The questions were adapted from the Ethiopia Demographic and Health Survey (EDHS) 2011 and from other studies but modified accordingly.

A seven day self-recall method was used for assessing exclusive breastfeeding. Ten female diploma nurses were recruited for data collection and two Bachelor of Science nurses for supervision, with all attending a one-day training prior to data collection.

\section{Operational definitions}

\section{Exclusive breastfeeding}

If an infant less than six months old took only breast milk and no additional food, water, or other liquids (with the exception of medicine and vitamins, if needed) during the seven days before the interview was conducted.

\section{Predominant breastfeeding}

If the infant's predominant source of nourishment is breast milk but additionally took liquid foods including water, tea, cow/formula milk, juice, or salt/sugar solution during the seven days before the interview was conducted.

\section{Partial breastfeeding}

If the infant took breast milk and in addition soft foods like mashed potatoes/meat, fruits, porridge, egg, butter and liquids like cow/formula milk, water, tea, juice, or salt/sugar solution during the seven days before the interview was conducted.

\section{Replacement feeding}

If the infant took only soft foods like mashed potatoes/ meat, fruits, porridge, egg, butter and liquids like cow/ formula milk, water, tea, juice, or salt/sugar solution during the seven days before the interview was conducted.

\section{Prelacteal feeding}

If an infant during the first three days of life took something other than breast milk.

\section{Adequate knowledge about breastfeeding}

Seven questions were asked to measure breastfeeding knowledge. If a mother could answer four or more questions correctly she was assessed as having adequate knowledge. The questions were adapted from previous similar unpublished thesis reports as well as the Infant and Young Child Feeding Strategy of Ethiopia [2].

\section{Statistical analysis}

Data were checked for completeness and entered (double entry) into Epi Info version 3.5.3. Data were cleaned and coded using Epi Info and transferred to SPSS version 20 for analysis.

Descriptive statistics were used to characterize respondents using different variables of interest. First, bivariate logistic regression analysis was undertaken for each explanatory variable with the outcome variable (exclusive breastfeeding). Variables with a p-value $\leq 0.2$ on bivariate logistic regression analysis were included in the multivariate logistic regression analysis. Statistical significance was determined using odds ratio with a 95\% confidence interval. Statistical significance was declared if $\mathrm{p}$-value was $<0.05$. 
Ethical approval was obtained from the Institutional Review Board of the Institute of Public Health, College of Medicine and Health Sciences, University of Gondar. A supporting letter was also provided by Debre Markos administration health office to conduct the research. In addition, informed verbal consent was obtained from the respondents before interviewing. Respondents were told about the aim of the study and confidentiality of the information they provided. Participants were informed that they had the right to withdraw from the study at any time. At the end of the interview mothers were informed about the benefits of breastfeeding for infants as well as for themselves and the risks of not breastfeeding.

\section{Results}

\section{Socio-demographic characteristics}

Of the 423 eligible mothers, 413 agreed to participate in the study, which made a response rate of $97.6 \%$. Three hundred and sixty study participants were Amhara (87.2\%), 36 (8.7\%) Awi and 11 (4.1\%) other ethnicities including Tigre and Oromo (Table 1). With regard to religion, the majority (83.8\%) were orthodox Christian. The mean age of the mothers was 29.2 years (standard deviation, $\mathrm{SD} \pm 4.9$ ). The mean age of the infants was 3.4 months $(\mathrm{SD} \pm 1.6)$.

\section{Maternal and child health service utilization characteristics}

The majority $(78 \%)$ of mothers had antenatal care during their pregnancy, but only $47.9 \%$ received counseling concerning breastfeeding during their care (Table 2). The majority $(72.6 \%)$ of the study participants had a postnatal care visit within 45 days of giving birth, and $67.3 \%$ were counseled about infant feeding at this visit.

\section{Breastfeeding information and knowledge}

The majority (90.1\%) of study participants had received breastfeeding information (Table 3). Over two thirds (61.7\%) of mothers did not have adequate knowledge of breastfeeding. More than half (57.4\%) of mothers knew that the first milk (colostrum) should be given to an infant (Table 4).

\section{Breastfeeding practice}

In this study all participants had initiated breastfeeding. Two hundred and fourteen respondents $(51.8 \%)$ initiated breastfeeding immediately/within one hour of birth. The majority $(75.8 \%)$ of infants were given prelacteal feeding. The prevalence of exclusive breastfeeding during the seven days before the interview was $60.8 \%$ (95\% CI: $55.8 \%, 65.8 \%$ ). Common reasons reported by mothers for not feeding breast milk only during the first six months of life includs; breastfeeding is not compatible with work, breastfeeding only is not sufficient for an infant, and they did not have enough milk (Table 5).
Table 1 Socio-demographic characteristics of mothers with infants aged less than six months, Debre Markos, Northwest Ethiopia, April 2013

\begin{tabular}{|c|c|c|c|}
\hline & Category $(n=413)$ & Number & Percent \\
\hline \multirow[t]{2}{*}{ Sex of infant } & Male & 219 & 53.0 \\
\hline & Female & 194 & 47.0 \\
\hline \multirow[t]{3}{*}{ Age of infant (days) } & $<60$ & 79 & 19.1 \\
\hline & $60-120$ & 164 & 39.7 \\
\hline & $121-179$ & 170 & 41.2 \\
\hline \multirow[t]{5}{*}{ Age of mother (years) } & $15-19$ & 22 & 5.3 \\
\hline & $20-24$ & 76 & 18.4 \\
\hline & $25-29$ & 150 & 36.3 \\
\hline & $30-34$ & 104 & 25.2 \\
\hline & $\geq 35$ & 61 & 14.8 \\
\hline \multirow[t]{4}{*}{ Religion of mother } & Orthodox & 346 & 83.8 \\
\hline & Muslim & 24 & 5.8 \\
\hline & Catholic & 20 & 4.8 \\
\hline & Protestant & 23 & 5.6 \\
\hline \multirow[t]{3}{*}{ Ethnicity of mother } & Amhara & 360 & 87.2 \\
\hline & Awi & 36 & 8.7 \\
\hline & Other* & 17 & 4.1 \\
\hline \multirow[t]{2}{*}{ Education of mother } & Not educated & 98 & 23.7 \\
\hline & Educated & 315 & 76.3 \\
\hline \multirow[t]{2}{*}{ Employment status of mother } & Unemployed & 166 & 40.2 \\
\hline & Employed & 247 & 59.8 \\
\hline \multirow[t]{5}{*}{ Marital status of mother } & Single & 21 & 5.1 \\
\hline & Married & 339 & 82.1 \\
\hline & Widowed & 18 & 4.4 \\
\hline & Divorced & 21 & 5.1 \\
\hline & Separated & 14 & 3.4 \\
\hline \multirow{2}{*}{$\begin{array}{l}\text { Education of husband } \\
(n=353)\end{array}$} & Not educated & 78 & 22.1 \\
\hline & Educated & 275 & 77.9 \\
\hline \multirow{2}{*}{$\begin{array}{l}\text { Employment status of } \\
\text { husband }(n=353)\end{array}$} & Unemployed & 21 & 5.9 \\
\hline & Employed & 332 & 94.1 \\
\hline \multirow[t]{2}{*}{ Type of family } & Nuclear & 280 & 67.8 \\
\hline & Extended & 133 & 32.2 \\
\hline \multirow[t]{3}{*}{ Monthly income ${ }^{* *}$} & $<818$ & 107 & 25.9 \\
\hline & $818-1968$ & 234 & 56.7 \\
\hline & $>1968$ & 72 & 17.4 \\
\hline
\end{tabular}

*Tigre, Oromo.

**Ethiopian birr.

\section{Factors associated with exclusive breastfeeding}

Hosmer-Lemeshow goodness-of-fit test $(p=0.617)$ was used to assess the fitness of the model. During the bivariate logistic regression analysis, educational status of the mother, employment status of mother, educational status of the husband, breastfeeding counseling during 
Table 2 Distribution of mothers with infants aged less than six months by maternal and child health service utilisation characteristics, Debre Markos, Northwest Ethiopia, April 2013

\begin{tabular}{|c|c|c|c|}
\hline Variable & Category $(n=413)$ & Number & Percent \\
\hline \multirow[t]{3}{*}{ Number of children } & 1 & 200 & 48.4 \\
\hline & $2-3$ & 182 & 44.1 \\
\hline & $\geq 4$ & 31 & 7.5 \\
\hline \multirow[t]{3}{*}{ Birth order of infant } & 1 & 201 & 48.7 \\
\hline & $2-3$ & 178 & 43.1 \\
\hline & $\geq 4$ & 34 & 8.2 \\
\hline \multirow[t]{2}{*}{ Antenatal care } & Yes & 322 & 78.0 \\
\hline & No & 91 & 22.0 \\
\hline \multirow{2}{*}{$\begin{array}{l}\text { Breastfeeding counseling } \\
\text { during antenatal care }\end{array}$} & Yes & 198 & 47.9 \\
\hline & No & 215 & 52.1 \\
\hline \multirow[t]{2}{*}{ Place of delivery } & Home & 67 & 16.2 \\
\hline & Health institution & 346 & 83.8 \\
\hline \multirow[t]{2}{*}{ Mode of delivery } & Normal/vaginal & 379 & 91.8 \\
\hline & $\mathrm{C} / \mathrm{S}$ & 34 & 8.2 \\
\hline \multirow[t]{2}{*}{ Postnatal care } & Yes & 300 & 72.6 \\
\hline & No & 113 & 27.4 \\
\hline \multirow{2}{*}{$\begin{array}{l}\text { Infant feeding counseling } \\
\text { during postnatal care }\end{array}$} & Yes & 278 & 67.3 \\
\hline & No & 135 & 32.7 \\
\hline
\end{tabular}

ANC, infant feeding counseling during PNC, colostrum feeding, prelacteal feeding and knowledge about breastfeeding were significantly associated with EBF.

During the multivariate logistic regression analysis; occupation of mother, breastfeeding counseling during ANC, infant feeding counseling during PNC, prelacteal feeding and knowledge about breastfeeding were significantly associated with EBF practice. But, educational status of the mother, educational status of the husband and colostrum feeding were not associated with EBF practice.

Unemployed mothers were 1.98 times more likely to exclusively breastfeed than employed mothers $[\mathrm{AOR}=1.98$ (1.21, 3.22)] (Table 6). Mothers who received counseling about breastfeeding during ANC were 2.44 times more likely to exclusively breastfed their infants compared to those who didn't receive counseling $[\mathrm{AOR}=2.44(1.53$, 3.91)]. Receiving counseling during PNC concerning infant feeding increased the likelihood of mothers feeding breast milk only by 5.03 times when compared to those who received no counseling during $\mathrm{PNC}[\mathrm{AOR}=5.03$ $(3.04,8.31)]$. Those mothers who didn't give prelacteal feeding for their infant were 3.44 times more likely to exclusively breastfeed compared to those who gave prelacteal feeds $[\mathrm{AOR}=3.44(1.88,6.33)]$. Mothers who had adequate knowledge about breastfeeding were 2.57 times more
Table 3 Distribution of mothers with infants aged less than six months by information access and breastfeeding knowledge characteristics, Debre Markos, Northwest Ethiopia, April 2013

\begin{tabular}{llll}
\hline Variable & Category $(\mathbf{n}=\mathbf{4 1 3})$ & Number & Percent \\
\hline Media access & Radio only & 52 & 12.6 \\
& Television only & 142 & 34.4 \\
& Both radio and television & 162 & 39.2 \\
& Neither radio or television & 57 & 13.8 \\
Information ever heard & Yes & 372 & 90.1 \\
about breastfeeding & No & 41 & 9.9 \\
Source of information & Radio & 105 & 25.4 \\
about breastfeeding* & Television & 215 & 52.1 \\
& HEWs & 207 & 50.1 \\
& Other HWs & 173 & 41.9 \\
& VCHWs & 36 & 8.7 \\
& Family/friend/neighbor & 71 & 17.2 \\
Breastfeeding knowledge & Adequate & 158 & 38.3 \\
& Not adequate & 255 & 61.7 \\
\hline
\end{tabular}

*sum of percent $>100$ due to multiple response options. HEWs - health extension workers. HWs - health workers.

VCHWs - volunteer community health workers.

likely to exclusively breastfeed their infants than those who didn't have adequate knowledge on breastfeeding $[\mathrm{AOR}=2.57(1.57,4.19)]$.

\section{Discussion}

The single most effective intervention for preventing child morbidity and mortality is practicing exclusive breastfeeding during the first six months of life [11]. In this study the prevalence of exclusive breastfeeding practice during the seven days before the interview was $60.8 \%$, which almost meets the HSDP IV target of $70 \%$ by the end of 2015 [9]. The rate of exclusive breastfeeding practice was higher in this study than the national prevalence of 52\% reported in the EDHS 2011 report [8].

The prevalence of EBF in this study is also higher than reported in previous international studies in the USA $16.8 \%$ [12], Brazil 29.8\% [13], Klang Malaysia 32.8\% [14], Peninsular Malaysia 43.1\% [15], Tamil Nadu India 34\% [16], Maharashtra India 36.84\% [17], Al-Hassa Saudi Arabia 24.4\% [18], Egypt 9.7\% [19], Nigeria 31\% [20], Western Tanzania 58\% [21], Harar Eastern Ethiopia 51.8\% [10], Arbaminch Southern Ethiopia 46.5\% [22] and Mida-Woremo district of Northern Ethiopia 58.3\% [23]. Some previous studies have identified higher rates of exclusive breastfeeding, including research at an urban health centre in Western India 61.5\% [24], 
Table 4 Breastfeeding knowledge of mothers with infants aged less than six months in Debre Markos Town, Northwest Ethiopia, April $2013(n=413)$

\begin{tabular}{|c|c|c|c|c|}
\hline No. & Question & Response & Number & Percent \\
\hline \multirow[t]{2}{*}{1.} & \multirow[t]{2}{*}{ Is breastfeeding important for child health? } & Agree & 349 & 84.5 \\
\hline & & Don't agree/don't know & 64 & 15.5 \\
\hline \multirow[t]{2}{*}{2.} & \multirow[t]{2}{*}{ Is breastfeeding important for maternal health? } & Agree & 91 & 22.0 \\
\hline & & Don't agree/don't know & 322 & 78.0 \\
\hline \multirow[t]{2}{*}{3.} & \multirow[t]{2}{*}{ Should an infant be put to breast immediately after birth? } & Agree & 259 & 62.7 \\
\hline & & Don't agree/don't know & 154 & 37.3 \\
\hline \multirow[t]{2}{*}{4.} & \multirow[t]{2}{*}{ Should the first milk/colostrum be given to an infant? } & Agree & 237 & 57.4 \\
\hline & & Don't agree/don't know & 176 & 42.6 \\
\hline \multirow[t]{2}{*}{5.} & \multirow[t]{2}{*}{ Is prelacteal feeding needed for an infant before starting breast milk? } & Agree & 262 & 63.4 \\
\hline & & Don't agree/don't know & 151 & 36.6 \\
\hline \multirow[t]{2}{*}{6.} & \multirow{2}{*}{$\begin{array}{l}\text { Is breast milk alone without water and other liquids enough for } \\
\text { an infant during the first } 6 \text { months of life? }\end{array}$} & Agree & 147 & 35.6 \\
\hline & & Don't agree/don't know & 266 & 64.4 \\
\hline \multirow[t]{2}{*}{7.} & \multirow{2}{*}{$\begin{array}{l}\text { Starting from } 6 \text { months, should an infant start complementary } \\
\text { feeding and continued breastfeeding up to } 2 \text { years and beyond? }\end{array}$} & Agree & 124 & 30.0 \\
\hline & & Don't agree/don't know & 289 & 70.0 \\
\hline
\end{tabular}

Zahedan Iran 98\% [25] and the Goba district of South East Ethiopia 71.3\% [26]. This variation might be due to methodological, time, socio-demographic, economic and cultural differences across areas.

Among the various socio-demographic factors assessed in this study only employment status of the mother was significantly associated with exclusive breastfeeding practice. Mothers who were unemployed were 1.98 times more likely to practice exclusive breastfeeding than employed mothers. This is in line with the study findings from Klang Malaysia [14], Peninsular Malaysia [15], Tamil Nadu India [16], Goba district [26], Arbaminch Ethiopia [22] and Mida-Woremo district Ethiopia [23]. This could be due to the fact that employed mothers may not have adequate time to feed breast milk to their infants during working hours.

Table 5 Distribution of mothers with infants aged less than six months by breastfeeding practices, Debre Markos, Northwest Ethiopia, April 2013

\begin{tabular}{|c|c|c|c|}
\hline Variable & Category $(n=413)$ & Number & Percent \\
\hline \multirow[t]{2}{*}{ Initiation of breastfeeding after birth } & Immediately/within 1 hour & 214 & 51.8 \\
\hline & After 1 hour & 199 & 48.2 \\
\hline \multirow[t]{2}{*}{ Colostrum feeding } & Yes & 259 & 62.7 \\
\hline & No & 154 & 37.3 \\
\hline \multirow[t]{2}{*}{ Prelacteal feeding } & No & 100 & 24.2 \\
\hline & Yes & 313 & 75.8 \\
\hline \multirow[t]{4}{*}{ Infant feeding during the seven days before interview } & Exclusive breastfeeding & 251 & 60.8 \\
\hline & Predominant breastfeeding & 115 & 27.8 \\
\hline & Partial breastfeeding & 38 & 9.2 \\
\hline & Replacement feeding & 9 & 2.2 \\
\hline \multirow[t]{7}{*}{ Reasons not feeding breast milk only $(n=162)$} & Not compatible with work & 45 & 27.8 \\
\hline & Breastfeeding only is not sufficient & 38 & 23.5 \\
\hline & Breast produce less milk & 27 & 16.7 \\
\hline & Infant thirsty & 22 & 13.6 \\
\hline & Mother ill/weak & 13 & 8.0 \\
\hline & Breast/nipple problem & 11 & 6.8 \\
\hline & Other & 6 & 3.7 \\
\hline
\end{tabular}


Table 6 Bivariate and multivariate logistic regression analysis showing factors associated with EBF practice of mothers with infants aged $<6$ months in Debre Markos, Northwest Ethiopia, April 2013

\begin{tabular}{|c|c|c|c|c|}
\hline \multirow[t]{2}{*}{ Variable } & \multicolumn{2}{|c|}{ Exclusive breastfeeding } & \multirow{2}{*}{$\begin{array}{l}\text { Crude odds } \\
\text { ratio }(95 \% \mathrm{Cl})\end{array}$} & \multirow{2}{*}{$\begin{array}{l}\text { Adjusted odds } \\
\text { ratio }(95 \% \mathrm{Cl})\end{array}$} \\
\hline & Yes (\%) & No (\%) & & \\
\hline \multicolumn{5}{|c|}{ Education of mother } \\
\hline Not educated & $51(12.3)$ & $47(11.4)$ & 1 & \\
\hline Educated & $200(48.4)$ & $115(27.8)$ & $1.6(1.01,2.53)$ & \\
\hline \multicolumn{5}{|c|}{ Employment status of mother } \\
\hline Unemployed & $115(27.8)$ & $51(12.3)$ & $1.84(1.22,2.79)$ & $1.98(1.21,3.22)^{*}$ \\
\hline Employed & $136(32.9)$ & $111(26.9)$ & 1 & 1 \\
\hline \multicolumn{5}{|c|}{ Education of husband } \\
\hline Not educated & $36(8.7)$ & $42(10.2)$ & 1 & \\
\hline Educated & $168(40.7)$ & $107(25.9)$ & $1.83(1.10,3.04)$ & \\
\hline No husband & $47(11.4)$ & $13(3.1)$ & $4.22(1.98,9.00)$ & \\
\hline \multicolumn{5}{|c|}{ Breastfeeding counseling during antenatal care } \\
\hline Yes & $142(34.4)$ & $56(13.6)$ & $2.47(1.64,3.71)$ & $2.44(1.53,3.91)^{*}$ \\
\hline No & $109(26.4)$ & $106(25.7)$ & 1 & 1 \\
\hline \multicolumn{5}{|c|}{ Infant feeding counseling during postnatal care } \\
\hline Yes & $199(48.2)$ & $79(19.1)$ & $4.02(2.61,6.20)$ & $5.03(3.04,8.31)^{*}$ \\
\hline No & $52(12.6)$ & $83(20.1)$ & 1 & 1 \\
\hline \multicolumn{5}{|c|}{ Colostrum feeding } \\
\hline Yes & $168(40.7)$ & $91(22.0)$ & $1.58(1.05,2.37)$ & \\
\hline No & $83(20.1)$ & $71(17.2)$ & 1 & \\
\hline \multicolumn{5}{|c|}{ Prelacteal feeding } \\
\hline No & $82(19.9)$ & $18(4.4)$ & $3.88(2.23,6.77)$ & $3.44(1.88,6.33)^{*}$ \\
\hline Yes & $169(40.9)$ & $144(34.9)$ & 1 & 1 \\
\hline \multicolumn{5}{|c|}{ Knowledge on breastfeeding } \\
\hline Adequate & $119(28.8)$ & $39(9.4)$ & $2.84(1.84,4.40)$ & $2.57(1.57,4.19)^{*}$ \\
\hline Not adequate & $132(32.0)$ & $123(29.8)$ & 1 & 1 \\
\hline
\end{tabular}

*P value $<0.05$ Backward stepwise logistic regression method.

In this study counseling about breastfeeding during ANC was significantly associated with exclusive breastfeeding for infants less than six months old. Those mothers who received counseling about breastfeeding during ANC were 2.44 times more likely to exclusively breastfed their infants compared to those who didn't receive counseling. This is consistent with the study findings from Egypt [19], Nigeria [27], Harar, Ethiopia [10], Arbaminch, Ethiopia [22] and Mida-Woremo district, Ethiopia [23]. This could be due to the start of an urban health extension program which increases the number of women who receive ANC services including breastfeeding counseling that in turn improves breastfeeding knowledge of mothers.

Infant feeding counseling during PNC is another maternal and child health service factor that has a significant association with EBF. Those mothers who received counseling concerning infant feeding during PNC were 5.03 times more likely to feed breast milk only for their infants than those not counseled. This is in line with a study finding from an urban health centre of Western India [24]. This might be the result of increased expansion of health facilities with trained health professionals especially midwives who teach mothers appropriate infant and young child feeding practices.

Prelacteal feeding influences EBF adversely. It also shows a significant association with EBF in this study. Those mothers who didn't give prelacteal feeds for their infant were 3.44 times more likely to exclusively breastfeed compared to those who gave prelacteal feeding. This is also consistent with a study finding from Saudi Arabia [18]. This could be explained by the fact that infants who were given prelacteal feeding may not adequately suckle their mothers' breast which in turn decreases milk production. The decrease in milk production will lead mothers to introduce complementary foods early (before 6 months) for their infants. 
Another factor that was shown to have a significant association with EBF is mothers' breastfeeding knowledge. Mothers who had adequate knowledge about breastfeeding were 2.57 times more likely to exclusively breastfeed their infants than those who didn't have adequate knowledge about breastfeeding. This has similarities with study findings from Nepal [28], Tunisia [29] and Tanzania [21]. This impact could be partly explained by mothers improved knowledge of the benefits of breastfeeding for themselves and their infants, as well as the risks of not breastfeeding, improving the likelihood mothers will breastfeed their infants even if alternatives are available.

\section{Conclusions}

Although the prevalence of exclusive breastfeeding in the previous seven days was lower in the study area than international recommendations, rates were higher than found in other studies. Employment status of the mother, breastfeeding counseling during ANC, infant feeding counseling during PNC, prelacteal feeding and mothers' knowledge about breastfeeding were independently and significantly associated with exclusive breastfeeding practice. Recommendations for improving EBF practices include better support for working mothers by extending maternal leave and establishing work-site day care centers for infants, expanding the urban health extension program so that more pregnant women and mothers can be taught about appropriate infant and young child feeding practices including how to express their milk if they are separated from their child.

\section{Competing interests}

The authors declare that they have no competing interests.

\section{Authors' contributions}

GM conceived and designed the study, performed analysis and interpretation of data and drafted the manuscript. ME assisted with the design, conception, analysis and interpretation of data, and the critical review of the manuscript. All authors read and approved the final manuscript.

\section{Acknowledgements \\ First, we would like to thank the University of Gondar for financial support to undertake the study. We would also like to thank Debre Markos administration health office for their support to conduct the study and for providing all the required information. Finally, a special thank you to all respondents (mothers) for their genuine response during the interviews and the data collectors and supervisors for their cooperation, commitment and honesty.}

\section{Author details \\ ${ }^{1}$ College of Medicine and Health Sciences, Department of Public Health, Debre Markos University, Debre Markos, Ethiopia. ${ }^{2}$ Institute of Public Health, College of Medicine and Health Sciences, Department of Applied Human Nutrition, University of Gondar, Gondar, Ethiopia.}

Received: 22 October 2013 Accepted: 15 December 2014 Published online: 20 January 2015

\section{References}

1. United States Department of Health and Human Services. The Surgeon General's Call to Action to Support Breastfeeding. Washington, DC: U.S. Department of Health and Human Services, Office of the Surgeon General; 2011.

2. Federal Ministry of Health. National Strategy for Infant and Young Child Feeding (IYCF). Ethiopia: Federal Ministry of Health, Family Health Department; 2004.
3. United Nations Children's Fund. Improving Exclusive Breast Feeding Practices by using Communication for Development in Infant and young Child Feeding Programs. United Nations Children's Fund; 2010.

4. World Health Organization. Global Health Risks; Mortality and Burden of Disease Attributable to Selected Major Risks. Geneva: World Health Organization; 2009.

5. World Health Organization. Infant and Young Child Feeding (IYCF) Model Chapter for Textbooks for Medical Students and Allied Health Professionals. Geneva: World Health Organization; 2009.

6. World Health Organization. Global Strategy for Infant and Young Child Feeding. Geneva: World Health Organization; 2003.

7. United Nations Children's Fund. Tracking Progress on Child and Maternal Nutrition; a Survival and Development Priority. New York: United Nations Children's Fund; 2009.

8. Central Statistical Agency [Ethiopia] and ICF International. Ethiopia Demographic and Health Survey (EDHS) 2011. Addis Ababa, Ethiopia and Calverton, Maryland, USA: Central Statistical Agency and ICF International; 2012.

9. Federal Democratic Republic of Ethiopia Ministry of Health. Health Sector Development Program IV 2010/11-2014/15. Federal Democratic Republic of Ethiopia Ministry of Health; 2010

10. Abera K. Infant and young child feeding practices among mothers living in Harar, Ethiopia. Harar Bull Health Sci. 2012;4:66-78.

11. Alive \& Thrive. Exclusive breastfeeding. [http://www.aliveandthrive.org/ourfocus-areas/exclusive]

12. Jones JR, Kogan MD, Singh GK, Dee DL, Grummer-Strawn LM. Factors associated with exclusive breastfeeding in the United States. Pediatrics. 2011;128:1117-25.

13. Queluz MC, Pereira MB, Santos CB, Leite AM, Ricco RG. Prevalence and determinants of exclusive breastfeeding in the city of Serrana, São Paulo, Brazil. Rev Esc Enferm USP. 2012:46:537-43.

14. Tan KL. Knowledge, attitude and practice on breastfeeding in Klang, Malaysia. Int Med J. 2009;8:17-22.

15. Tan KL. Factors associated with exclusive breastfeeding among infants under six months of age in peninsular Malaysia. Int Breastfeed J. 2011;6:2

16. Radhakrishnan S, Balamuruga SS. Prevalence of exclusive breastfeeding practices among rural women in Tamil Nadu. Int J Health Allied Sci. 2012;1:64-7.

17. Bagul AS, Supare MS. The infant feeding practices in an urban slum of Nagpur, India. J Clin Diagn Res. 2012;6:1525-7.

18. El-Gilany A, Shady E, Helal R. Exclusive breastfeeding in Al-Hassa, Saudi Arabia. Breastfeed Med. 2011;6:4

19. Al Ghwass MM, Ahmed D. Prevalence and predictors of 6-month exclusive breastfeeding in a rural area in Egypt. Breastfeed Med. 2011;6:209-13.

20. Oche MO, Umar AS, Ahmed $\mathrm{H}$. Knowledge and practice of exclusive breastfeeding in Kware, Nigeria. Afr Health Sci. 2011;11:518-23.

21. Nkala TE, Msuya SE. Prevalence and predictors of exclusive breastfeeding among women in Kigoma region, Western Tanzania: a community based cross-sectional study. Int Breastfeed J. 2011;6:17.

22. Echamo M. Exclusive breast feeding in Arbaminch, SNNPR, Ethiopia. Harar Bull Health Sci. 2012;5:44-59.

23. Fanosie F. Exclusive breast feeding practices in Mida-Woremo District, Amhara Region, Ethiopia. Harar Bull Health Sci. 2011;2:57-70.

24. Patil SS, Hasamnis AA, Pathare RS, Parmar A, Rashid AK, Narayan KA. Prevalence of exclusive breast feeding and its correlates in an Urban Slum in Western India. Int J Sci Med Educ. 2009;3:14-8.

25. Roudbari M, Roudbari S, Fazaeli A. Factors associated with breastfeeding patterns in women who recourse to health centers in Zahedan, Iran. Singapore Med J. 2009;50:181-4.

26. Setegn T, Belachew T, Gerbaba M, Deribe K, Deribew A, Biadgilign S. Factors associated with exclusive breastfeeding practices among mothers in Goba district, Southeast Ethiopia: a cross-sectional study. Int Breastfeed J. 2012;7:17.

27. Agho KE, Dibley MJ, Odiase Jl, Ogbonmwan SM. Determinants of exclusive breastfeeding in Nigeria. BMC Pregnancy Childbirth. 2011;11:2.

28. Ulak M, Chandyo RK, Mellander L, Shrestha PS, Strand TA. Infant feeding practices in Bhaktapur, Nepal: a cross-sectional, health facility based survey. Int Breastfeed J. 2012;7:1.

29. Bouanene I, ElMhamdi S, Sriha A, Bouslah A, Soltani M. Knowledge and practices of women in Monastir, Tunisia regarding breastfeeding. East Mediterr Health J. 2010;16:879-85. 